\title{
UMA HISTÓRIA PARA O INVENTÁRIO ARQUIVÍSTICO DO DEPARTAMENTO DE MATEMÁTICA DA UEM
}

\section{A STORY ABOUT THE INVENTORY OF THE ARCHIVE OF MATH DEPARTMENT AT UEM}

\author{
Suélen Rita Andrade Machado ${ }^{1}$ \\ Universidade Estadual de Maringá \\ Lucieli M. Trivizoli ${ }^{2}$ \\ Universidade Estadual de Maringá
}

\section{Resumo}

Com o objetivo de identificar, organizar e catalogar um número expressivo de documentos que haviam sido localizados durante o desenvolvimento de pesquisas sobre o histórico do Curso de Matemática da Universidade Estadual de Maringá, um grupo de pesquisadores idealizou um processo de agrupamento documental, que compôs o recém constituído inventário arquivístico para o Departamento de Matemática da UEM. Nesse artigo apresentamos uma caracterização histórica desse processo de preservação da memória institucional do Departamento de Matemática da Universidade Estadual de Maringá - UEM, a partir da identificação e organização de fontes primárias datadas de 1971 a 1996. Destacamos os procedimentos metodológicos utilizados para a manipulação de fontes arquivísticas bem como os percalços quanto a natureza da preservação documental. Evidenciamos possíveis articulações investigativas entre a História Institucionais de Cursos de Matemática, a História da Matemática e a História da Educação Matemática a partir da preservação física dos arquivos, que possibilita a elaboração de discursos sobre a história, algo possível mediante a análise e interpretação de contextos e situações que estão implícitas nos documentos. Nossas discussões ampliam o espaço de divulgação e o conhecimento advindo dos documentos preservados e oportunizam uma possível história para o recém constituído inventário arquivístico, que carrega consigo momentos históricos que acompanham os primeiros vinte cinco anos de existência do Curso de Matemática da UEM, a partir da bibliografia já publicada acerca de alguns desses documentos. Entendemos que a divulgação deste inventário pode fortalecer o cenário investigativo na construção de conhecimentos históricos pluridisciplinares pelos vieses historiográficos de abrangências diversas, bem como a preservação adequada de documentos públicos, que devem ser acessíveis à sociedade.

Palavras-chave: Preservação Memorística. História da Educação Matemática. História Institucional.

\begin{abstract}
In order to identify, organize and catalog a significant number of documents that had been identified during the development of research about the history of the Mathematics Course of the State University of Maringá (UEM), a group of researchers developed a
\end{abstract}

\footnotetext{
${ }^{1}$ sumachado18@gmail.com

2 lmtrivizoli@uem.br
} 
process of documental organization, which composed the newly constituted archival inventory for the Mathematics Department of the UEM. In this paper we present a historical characterization of this process of preservation for the institutional memory of the Department of Mathematics of UEM, from the identification and organization of primary sources dating from 1971 to 1996. It highlights the methodological procedures used for the manipulation of sources as well as mishaps to the nature of document preservation. It shows possible investigative articulations between the Institutional History of Mathematics Courses, the History of Mathematics and the History of Mathematical Education from the physical preservation of archives, which enables the elaboration of historical discourses, something achievable through the analysis and interpretation of contexts and situations that are implicit in the documents. Our arguments expands the space of dissemination and the knowledge coming from the preserved documents and provides a possible history for the newly constituted archival inventory, which carries with its historical moments included in the first twenty-five years of existence of the Mathematics Course of UEM, based on the bibliography that has been published about some of these documents. We understand that the disclosure of this inventory may strengthen the investigative scenario in the construction of multidisciplinary historical knowledge by different historiographical scopes, as well as the preservation of public documents properly that should be accessible to overall users.

Keywords: Memoristic Preservation. History of Mathematical Education. Institutional History.

\section{Introdução}

Estudos e pesquisas recentes em História da Matemática e História da Educação Matemática vêm apontando diversos caminhos e focos de abordagem, como as histórias de conceitos, histórias da própria disciplina Matemática, das instituições, das biografias de matemáticos e professores de Matemática, suscitando uma demanda crescente para a preservação da memória e de sua divulgação (GARNICA; SOUZA, 2012).

Temos, portanto, as informações primárias provenientes de documentos e arquivos entre os possíveis caminhos para as construções historiográficas. E uma das preocupações, quando se trata da escrita da História da Matemática no Brasil, é a preservação de arquivos, de documentos e da própria memória em nossas instituições.

Entendemos, então, que são possíveis as articulações investigativas entre a História Institucional de Cursos de Matemática, a História da Matemática e a História da Educação Matemática, indicadas pela variedade de procedimentos e instrumentos de coleta de dados inerentes a abordagem qualitativa de pesquisas (FLICK, 2004; BOGDAN; BIKLEN, 1994).

Nesse sentido, essas articulações atreladas a divulgação de histórias recentes consolidam-se neste artigo, em uma caracterização pública para o processo de preservação da memória institucional do Departamento de Matemática da Universidade 
Suélen Rita Andrade Machado; Lucieli M. Trivizoli

Uma história para o inventário arquivístico do departamento de matemática da UEM

Estadual de Maringá - UEM, a partir da identificação e organização de fontes primárias ${ }^{3}$ datadas de 1971 a 1996.

Sabemos que há percalços quanto a natureza de preservação documental, neste sentido, faremos uma breve exposição acerca deste importante legado instrumental para os historiadores, com base na pesquisa bibliográfica, a partir de "[...] um apanhado geral sobre os principais trabalhos já realizados, revestidos de importância, por serem capazes de fornecer dados atuais e relevantes relacionados com o tema" (MARCONI; LAKATOS, 2003, p. 158).

Neste texto localizaremos o leitor acerca do processo de preservação da memória institucional do Departamento de Matemática idealizado por um grupo de pesquisadores da Universidade Estadual de Maringá e apresentaremos o inventário arquivístico dos documentos encontrados. Para esta etapa, nos fundamentaremos em pesquisas que foram publicadas por estes pesquisadores e são relacionadas à organização dos arquivos que foi realizada. Por fim, considerações sobre o objeto deste trabalho serão lançadas de modo a contribuir com o discurso de preservação, divulgação e construção de conhecimentos a partir da história e das memórias institucionais.

\section{Preservação de documentos e arquivos}

Tomamos como definição para documentos a que é trazida pelo Arquivo Nacional, que define este como: "Unidade de registro de informações, qualquer que seja o suporte" (ARQUIVO NACIONAL, 2005, p. 73). Para arquivos, entendemos como sendo um conjunto documental gerado por uma instituição pública ou privada no decorrer de suas funções (ARQUIVO NACIONAL, 2005). Destacamos, a importância da preservação do patrimônio documental, como exercício do registro do direito, do poder e da memória social e individual, uma vez que

O documento ou, ainda, a informação registrada, sempre foi o instrumento de base do registro das ações de todas as administrações, ao longo de sua produção e utilização, pelas mais diversas sociedades e civilizações, épocas e regimes (INDOLFO, 2007, p. 29).

Temos ciência que “[...] No Brasil não há uma prática corriqueira de preservação documental privada, e as notícias de destruição de importantes conjuntos documentais

\footnotetext{
3 As fontes primárias, são documentos que não receberam nenhum tratamento analítico, logo são passíveis de análise (MARCONI; LAKATOS, 2003).
} 
Suélen Rita Andrade Machado; Lucieli M. Trivizoli

Uma história para o inventário arquivístico do departamento de matemática da UEM

infelizmente não são raras" (BACELLAR, 2008, p. 42). O que instala o descaso ao patrimônio arquivístico, materializado no armazenamento inadequado e precário de documentos. Porém, enfatizamos que a preservação da documentação armazenada nos arquivos é necessária, uma vez que os documentos públicos devem ser acessíveis à sociedade. Entretanto, é comum encontrar dificuldades para acessar documentos institucionais de uma maneira geral.

Muitas vezes, isso é consequência da ausência de tratamento arquivístico dos documentos produzidos pelas instituições, que segundo Indolfo (2007), deriva do desinteresse público e privado, que restringe o olhar apenas à liberação de espaço físico, quando a quantidade de documentos acumula-se:

\begin{abstract}
A ausência de elaboração e implantação de programas de gestão de documentos tem ocorrido de uma forma sistemática, em função da falta de recursos humanos capacitados para a execução de tal atividade e da falta de instrumentais técnicos indispensáveis para orientar os procedimentos fundamentais de classificação e organização, de análise e seleção documental. [...] A solução para os conjuntos documentais acumulados e para esses depósitos abarrotados de papéis é um dos grandes desafios para os serviços arquivísticos das administrações públicas, não só no Brasil (INDOLFO, 2007, p. 46).
\end{abstract}

Entendemos que para a preservação de arquivos, é necessário sobretudo a organização e localização preliminar dos documentos. Este processo é árduo, tendo em vista as condições aos quais esses documentos se encontram, como já mencionamos, e aqueles que, por alguma razão, foram extraviados ou perdidos com o tempo. Segundo Bacellar (2008), há procedimentos importantes para aqueles que se aventurarem nesta seara investigativa, como conhecer a origem processual dos documentos:

\begin{abstract}
-Descobrir onde se encontram os papéis que podem ser úteis para a pesquisa. -Preparar-se para enfrentar as condições de trabalho do arquivo escolhido. -Localizar as fontes no arquivo com base em instrumentos de pesquisa e investigações adicionais, munido de muita paciência. -Usar luvas, máscara e avental no contato direto com os documentos. -Manusear os papéis com cuidado, respeitando seus limites. Trabalhar com lupa de aumento e régua leve. Colocar sob o documento frágil uma folha de papel sulfite. -Manter os documentos guardados na ordem encontrada [...] (BACELLAR, 2008, p. 72).
\end{abstract}

Não há uma hierarquia para os procedimentos destacados, contudo, os que estão listados acima, podem auxiliar no processo de identificação e organização dos 
Suélen Rita Andrade Machado; Lucieli M. Trivizoli

Uma história para o inventário arquivístico do departamento de matemática da UEM

documentos. Conhecê-los, facilita a adaptação e o planejamento da realização do trabalho. Entendendo a natureza do material que se observa e tem em mãos, e principalmente o valor histórico inerente a ele.

Alertamos que, além da preservação física dos arquivos, também é possível a elaboração de discursos sobre a história, algo possível mediante a análise e interpretação de contextos e situações que estão implícitas nos documentos (MACHADO; TRIVIZOLI, 2018b). Isso corrobora na preservação da memória institucional, enquanto objeto de identidade histórica de contextos e situações.

$\mathrm{Na}$ sequência deste texto, caracterizaremos o processo de identificação e organização de fontes primárias localizadas em diferentes instâncias da Universidade Estadual de Maringá. Este processo levou cerca de seis anos (2012-2018) em virtude do tempo limitado da pesquisa e da permuta de pesquisadores, contudo, sua abrangência alcançou professores, graduandos, mestrandos e doutorandos. Para encadeamento e confirmação das informações, focalizaremos em pesquisas acadêmicas que foram publicadas concernentes à coleta e organização das fontes primárias do Departamento.

\section{O inventário documental do Departamento de Matemática da UEM}

Com o objetivo de identificar, organizar e catalogar um número expressivo de documentos que haviam sido localizados durante o desenvolvimento de pesquisas sobre o histórico do Curso de Matemática da UEM, um grupo de pesquisadores idealizou um processo de agrupamento documental, que futuramente compôs o recém constituído inventário arquivístico para o Departamento de Matemática da UEM.

Conforme informações coletadas em Araujo Neto, Gomes e Trivizoli (2013), o projeto que deu pontapé à especulação e garimpagem de arquivos, teve início em agosto de 2012, como projeto de iniciação científica, titulado: O curso de Matemática da Universidade Estadual de Maringá: um estudo histórico.

De início, a busca por informações relativas a criação do curso suscitou um impasse, devido a ausência de "[...] um centro arquivístico específico com todas as documentações dos cursos da UEM" (ARAUJO NETO; GOMES; TRIVIZOLI, 2013, p. 4). Foi preciso consultar profissionais ligados ao Departamento de Matemática, Centro de Ciências Exatas, Biblioteca Central, Divisão de Apoio aos Colegiados, Protocolo Geral, Apoio ao Colegiado Superior, Reconhecimento de Cursos de Graduação, dos quais foram obtidas informações relevantes segundo esses pesquisadores supracitados. 
Suélen Rita Andrade Machado; Lucieli M. Trivizoli

Uma história para o inventário arquivístico do departamento de matemática da UEM

Do período que se tratava essa pesquisa, poucos documentos haviam sido localizados em virtude da fase inicial de coleta, entretanto, os pesquisadores ressaltaram a localização de documentos como: a Resolução e a Ata que aprovou o curso de Matemática, junto ao Apoio ao Colegiado Superior. Ainda, foi buscado o acesso "[...] junto a Divisão de Apoio aos Colegiados, ao arquivo que contém os projetos políticopedagógicos do curso desde 1979, tendo em vista que foi neste ano que o Ministério da Educação instituiu a obrigatoriedade do arquivo dos processos" (ARAUJO NETO; GOMES; TRIVIZOLI, 2013, p. 4).

Para reunir os documentos e para oficialização dos trabalhos que estavam sendo realizados, foi submetido um projeto de pesquisa institucional pela docente coordenadora das ações (Processo 7789/2014). O projeto foi cadastrado no Sistema de Gerenciamento de Pesquisas (SGP) da UEM e abrangeu o período de 2014 a 2017.

Em prosseguimento a coleta de informações, encontramos o trabalho de Araujo Neto e Trivizoli (2014), no qual os pesquisadores advertem, outra vez, sobre o impasse da ausência de um centro arquivístico na instituição, mas relatam sobre o andamento do processo de organização dos arquivos até então coletados:

[...] iniciamos o trabalho de organização. Para tanto, estamos dispondo os documentos em ordem cronológica e agrupamos os que dizem respeito ao um assunto em comum. Estamos realizando, também, o fichamento dos arquivos. Cada ficha é dividida em três tópicos: assunto, documentos e adquiridos com. Para alocá-los, utilizamos pastas organizadoras (ARAUJO NETO; TRIVIZOLI, 2014, p. 7).

Os documentos, naquele momento, já estavam sendo alocados no Departamento de Matemática. Muitos deles foram encontrados soltos, dispersos e/ou em pastas num armário e no interior de caixas na sala de máquinas do antigo almoxarifado do Departamento de Matemática. Conforme relato dos pesquisadores:

[...] A primeira decisão foi organizar o material encontrado de acordo com os anos em que foram registrados. Assim, o trabalho é intenso, pois, para mantermos a ordenação cronológica dos documentos, precisamos ler cada um para ver qual o seu ano de origem, o que em certos documentos é um obstáculo, pois alguns não apresentam datas, por estarem dispersos, outros as datas estão apagadas devido ao tempo (ARAUJO NETO; TRIVIZOLI, 2014, p. 8). 
Suélen Rita Andrade Machado; Lucieli M. Trivizoli

Uma história para o inventário arquivístico do departamento de matemática da UEM

Ainda, para estes pesquisadores, da análise dos documentos localizados até aquele momento, foi possível encontrar: atas de reuniões, programa de disciplinas, eventos realizados, notas de alunos, documentos sobre vestibular, entre outros. As demais etapas referentes a organização, se valeriam da disposição cronológica deles.

Uma informação não encontrada nos demais trabalhos, mas em Gomes e Trivizoli (2015), diz respeito ao fato de que muitos dos documentos da Universidade foram perdidos na década de 1970 em virtude de uma inundação no local em que eram armazenados. O que pode ter ocasionado em perdas documentais significativas para escrita da história institucional desta universidade.

Entretanto, as pesquisadoras destacam que por meio do contato com professores do Departamento, foi possível localizar e recuperar informações relevantes acerca do início do curso, a partir do Livro de Catálogo dos Cursos da UEM, de 1971. Foi viável encontrar neste trabalho, menção aos documentos:

[...] livro Catálogo dos cursos de 1971 do Instituto de Ciências Exatas e Tecnológicas da UEM; do projeto político pedagógico de 1979; da Grade curricular contida no Projeto Pedagógico (Currículo) do curso de Matemática - Regime Seriado anual do ano de 1991; da proposta de alteração curricular no curso ofício $n^{\circ} 002 / 95-M A T$; da resolução $n^{\circ}$ 069/96-CEP, de 1996, com a aprovação de um novo currículo do curso de matemática e a criação da habilitação bacharelado; e da resolução $n^{\circ}$ 142/99 - CEP de 1999 com as alterações no currículo do curso de matemática (GOMES; TRIVIZOLI, 2015, p. 2).

No trabalho de Flavio e Trivizoli (2015), encontramos uma inventariação documental para a primeira década do Curso de Matemática da UEM. Muitos destes documentos são: ementas, programas, relação de professores que ministravam disciplinas, documentos referentes a criação de um programa de pós-graduação, dados sobre eventos, projetos, recortes de jornais entre outros:

Os documentos encontrados e organizados referentes a cada ano foram: 1971: informações de professores/disciplinas, grade das disciplinas do curso, informações sobre vestibulares e matriculados, programa das disciplinas. 1972: Informações de professores/disciplinas, programa das disciplinas, controle de matérias lecionadas, diários de classe. 1973: Programa das disciplinas, Diários de classe. 1974: Programa das disciplinas, professores/disciplinas, Alunos monitores. 1975: Professores/disciplinas, programa das disciplinas. 1976: Edital de notas, professores/disciplinas, programa das disciplinas, pós-graduação PUC-RJ/UEM. 1977: Edital de notas, programa das disciplinas. 1978: Professores/disciplinas, edital de 
notas, alunos monitores, programa das disciplinas. 1979: Professores/disciplinas, programa das disciplinas, ante projeto do curso de pós graduação sensu latu (FLAVIO; TRIVIZOLI, 2015, p. $3)$.

De acordo com Araujo Neto (2016), foram notáveis os desafios em relação a organização dos arquivos localizados, uma vez, que a sala de máquinas foi o lugar atribuído ao armazenamento da documentação inventariada e demais documentações que haviam sido encontradas, porém, não catalogadas. Em razão do espaço físico ser compartilhado, muitas vezes, as documentações organizadas eram encontradas desordenadas.

Contudo, a inventariação arquivística da primeira década foi notável e importante para iniciar a preservação da memória institucional, pois permitiu a realização da dissertação de Araujo Neto (2016), que estudou historicamente a criação e os primeiros anos do Curso de Matemática da UEM, a partir da História Oral e Documental. Ainda, pelo projeto de pesquisa institucional desenvolvido foi possível obter a relação dos professores que atuaram no Departamento de Matemática nos primeiros anos (até 1976) com a identificação da formação desses professores que vieram atuar na instituição. Essa identificação indicou que o corpo de professores contratado para atuar na recém criada Universidade Estadual de Maringá, em particular na área da Matemática, foi recrutado de outras regiões do estado e do país.

Com base na organização de documentos realizada previamente pelos pesquisadores supracitados, referente aos anos 1971 a 1982, realizamos também o processo de separação para arquivos dos anos 1983 a 1996, dispondo-os em ordem cronológica e agrupando-os em assuntos comuns. Após este procedimento, elaboramos o fichamento dos arquivos, quanto ao assunto, documentos e adquiridos com, alocandoos em pastas organizadoras, assim como procederam os outros pesquisadores (MACHADO; TRIVIZOLI, 2018a).

Concordamos com Araujo Neto (2016) que as condições de armazenamento dos documentos na sala de máquinas do departamento eram precárias em razão das adversidades físicas e naturais do local, o que podia acarretar no desgaste ou perda dos documentos, contatos com sujeira e insetos pelos pesquisadores, além de ser um local pequeno, no qual muitos outros equipamentos inutilizáveis eram remanejados para lá.

Entretanto, a última fase da organização corroborou com nossa pesquisa de mestrado que analisou as modificações curriculares do Curso de Matemática da UEM, 
Suélen Rita Andrade Machado; Lucieli M. Trivizoli

Uma história para o inventário arquivístico do departamento de matemática da UEM

considerando as mudanças do saber profissional docente, entre os anos 1971 a 1996

(MACHADO, 2019). A partir da nova fase de catalogação, foi possível também, encontrar documentos que propiciaram a produção de artigos que retratavam momentos históricos referentes a eventos sobre o Ensino da Matemática na década de 1980 (MACHADO; TRIVIZOLI, 2018b).

No Quadro 1, apresentamos a justaposição cronológica dos arquivos e por disposição no interior de cada pasta. Essa identificação prévia permite o acesso público aos documentos arquivados no Departamento de Matemática da UEM para leitura e análise de seu conteúdo.

Quadro 1 - Organização de Arquivos do Departamento de Matemática

\begin{tabular}{|c|c|}
\hline ANO / PASTA ARQUIVO & ARQUIVOS DIPOSTOS \\
\hline 1971 & $\begin{array}{l}\text {-Resultados Finais das Disciplinas; } \\
\text {-Dados do Curso (1971 a 1975); } \\
\text {-Grade das Disciplinas (1971, 1972, 1973, 1974); } \\
\text {-Programa das Disciplinas; } \\
\text {-Planos de Cursos I; } \\
\text {-Planos de Cursos II; } \\
\text {-Programas das Disciplinas (1972); } \\
\text {-Professores/Disciplinas (1971 a 1975); } \\
\text {-Resolução }{ }^{\circ} .01 / 70 \text { e ata; } \\
\text {-Parecer 227/70 - Resolução 01/70 - 5 } 5^{\text {a }} \text { Ata. }\end{array}$ \\
\hline 1972 & $\begin{array}{l}\text {-Professores/Disciplinas (1972 a 1976); } \\
\text {-Horário, Frequência e Informações dos Professores I; } \\
\text {-Horário, Frequência e Informações dos Professores II; } \\
\text {-Horário, Frequência e Informações dos Professores III } \\
\text { (Documentos Soltos); } \\
\text {-Controle de Matéria Lecionada; } \\
\text {-Programas das Disciplinas; } \\
\text {-Notas das Turmas (1972); } \\
\text {-Diários de Classe; } \\
\text {-ICET - Resolução 02/72; } \\
\text {-Decreto no. 70.156, de } 17 \text { de fevereiro de 1972. }\end{array}$ \\
\hline $\begin{array}{c}1973 \\
\text { PASTA ARQUIVO }(A)\end{array}$ & $\begin{array}{l}\text {-Alunos por Disciplina; } \\
\text {-Programas das Disciplinas ( }{ }^{\circ} \text { Semestre); } \\
\text {-Programas das Disciplinas ( } 2^{\circ} \text { Semestre); } \\
\text {-Diários de Classe. }\end{array}$ \\
\hline $\begin{array}{c}1973 \\
\text { PASTA ARQUIVO }(B)\end{array}$ & $\begin{array}{l}\text {-Programas das Disciplinas; } \\
\text {-Planos de Curso (2 Semestre de } 1973 / 1^{\circ} \text { Semestre de 1974); } \\
\text {-Matéria Lecionada }\left(1^{\circ} \text { Semestre de } 1973 / 2^{\circ} \text { Semestre de }\right. \\
\text { 1973/1º Semestre de 1974); } \\
\text {-Programa das Disciplinas I; } \\
\text {-Programa das Disciplinas II; } \\
\text {-Programa das Disciplinas III; } \\
\text {-Programa das Disciplinas IV; } \\
\text {-Programa das Disciplinas V. }\end{array}$ \\
\hline 1974 & $\begin{array}{l}\text {-Informação e Frequência dos Professores; } \\
\text {-Programas das Disciplinas; } \\
\text {-Programas das Disciplinas; } \\
\text {-Programas das Disciplinas I; } \\
\text {-Programas das Disciplinas I; }\end{array}$ \\
\hline
\end{tabular}


Suélen Rita Andrade Machado; Lucieli M. Trivizoli

Uma história para o inventário arquivístico do departamento de matemática da UEM

\begin{tabular}{|c|c|}
\hline & $\begin{array}{l}\text {-Programas das Disciplinas II; } \\
\text {-Programas das Disciplinas II; } \\
\text {-Programas das Disciplinas III; } \\
\text {-Alunos Monitores por Disciplina. } \\
\text {-Notas de Aula de Geometria Analítica e Álgebra Linear I; } \\
\text {-Notas de Aula de Geometria Analítica e Álgebra Linear II; } \\
\text {-Certidão } \mathrm{n}^{\circ} .657 / 74 \text {. }\end{array}$ \\
\hline 1975 & $\begin{array}{l}\text {-Professores/Disciplinas - Alunos Monitores; } \\
\text {-Diários de Classe; } \\
\text {-Informações/Frequência dos Professores; } \\
\text {-Documentos Avulsos (Programas, Histórico da Disciplina); } \\
\text {-Programa das Disciplinas; } \\
\text {-Programa das Disciplinas I; } \\
\text {-Programa das Disciplinas I; } \\
\text {-Programa das Disciplinas II; } \\
\text {-Programa das Disciplinas II; } \\
\text {-Programa das Disciplinas III; } \\
\text {-Programa das Disciplinas III; } \\
\text {-Programa das Disciplinas IV. }\end{array}$ \\
\hline 1976 & $\begin{array}{l}\text {-Calendário Acadêmico e Horário dos Turnos; } \\
\text {-Edital de Notas } 1^{\circ} \text { Semestre e } 2^{\circ} \text { Semestre de } 1976 ; \\
\text {-Cursos de Nivelamento e Pós-Graduação; } \\
\text {-Ementas. }\end{array}$ \\
\hline 1977 & $\begin{array}{l}\text {-Programas das Disciplinas I; } \\
\text {-Programas das Disciplinas I; } \\
\text {-Programas das Disciplinas II; } \\
\text {-Programas das Disciplinas II; } \\
\text {-Edital de Notas } 1^{\circ} \text { Semestre de } 1977 \text {; } \\
\text {-Edital de Notas } 2^{\circ} \text { Semestre de } 1977 .\end{array}$ \\
\hline 1978 & $\begin{array}{l}\text {-Alunos Monitores; } \\
\text {-Professores/Disciplinas; } \\
\text {-Programas das Disciplinas I; } \\
\text {-Programas das Disciplinas II; } \\
\text {-Programas das Disciplinas III; } \\
\text {-Edital de Notas } 1^{\circ} \text { Semestre de 1978; } \\
\text {-Edital de Notas 2 } 2^{\circ} \text { Semestre de 1978; } \\
\text {-Programas das Disciplinas Ministradas. }\end{array}$ \\
\hline 1979 & $\begin{array}{l}\text {-Planos de Ensino } 1^{\circ} \text { Semestre e } 2^{\circ} \text { Semestre de } 1979 ; \\
\text {-Relatório "Stricto Senso"; } \\
\text {-Controle Acadêmico } 1^{\circ} \text { Semestre e } 2^{\circ} \text { Semestre de } 1979 ; \\
\text {-PPP I - Processo } 0562 / 79 \text { - folhas } 02-124 ; \\
\text {-PPP I - Processo 0562/79 - folhas } 134-139 .\end{array}$ \\
\hline 1980 & $\begin{array}{l}\text {-Edital de Faltas } 1^{\circ} \text { Semestre de } 1980 ; \\
\text {-Edital de Faltas } 1^{\circ} \text { Semestre e } 2^{\circ} \text { Semestre; } \\
\text {-Programas das Disciplinas Ministradas } 1^{\circ} \text { Semestre de } 1980 ; \\
\text {-Planos de Ensino do } 1^{\circ} \text { Semestre de } 1980 ; \\
\text {-Planos de Ensino do } 1^{\circ} \text { Semestre de } 1980 ; \\
\text {-Documentos: Metas Básicas para o Curso e Docentes (1980 } \\
\text { a 1982); } \\
\text { - } 3^{\circ} \text { Congresso Brasileiro de Matemática Aplicada. }\end{array}$ \\
\hline 1981 & $\begin{array}{l}\text {-Edital de Notas } 1^{\circ} \text { Semestre de } 1981 ; \\
\text {-Programas das Disciplinas Ministradas; } \\
\text {-Catálogo de Ementas e Programas do } 1^{\circ} \text { Semestre e } 2^{\circ} \\
\text { Semestre I; } \\
\text {-Catálogo de Ementas e Programas do } 1^{\circ} \text { Semestre e } 2^{\circ} \\
\text { Semestre II; } \\
\text {-Catálogo de Ementas e Programas do } 1^{\circ} \text { Semestre e } 2^{\circ} \\
\text { Semestre III; } \\
\text {-Catálogo de Ementas e Programas do } 1^{\circ} \text { Semestre e } 2^{\circ}\end{array}$ \\
\hline
\end{tabular}


Suélen Rita Andrade Machado; Lucieli M. Trivizoli

Uma história para o inventário arquivístico do departamento de matemática da UEM

\begin{tabular}{|c|c|}
\hline & $\begin{array}{l}\text { Semestre IV; } \\
\text {-Catálogo de Ementas e Programas do } 1^{\circ} \text { Semestre e } 2^{\circ} \\
\text { Semestre V; } \\
\text {-Programas e Ementas; } \\
\text {-Resoluções e Relatórios; } \\
\text {-Horário dos Professores; } \\
\text {-I Encontro Do Ensino Da Matemática; } \\
\text {-Arquivos Avulsos. }\end{array}$ \\
\hline $\begin{array}{c}1982 \\
\text { PASTA ARQUIVO }(A)\end{array}$ & $\begin{array}{l}\text {-Horário de Professores; } \\
\text {-Resoluções; } \\
\text {-Relatórios de Disciplinas (1982 a 1983); } \\
\text {-Currículo do Curso de Licenciatura Matemática; } \\
\text {-Ementas; } \\
\text {-Relatórios de Matrícula } 1^{\circ} \text { Semestre de 1982; } \\
\text {-Relatórios de Matrícula 2 Semestre de 1982; } \\
\text {-Relatório de Monitoria de 1982; } \\
\text {-Relatório da Coordenação da Monitoria; } \\
\text {-Projeto do Curso de Mestrado I; } \\
\text {-Projeto do Curso de Mestrado II. }\end{array}$ \\
\hline $\begin{array}{c}1982 \\
\text { PASTA ARQUIVO }(B)\end{array}$ & $\begin{array}{l}\text {-Relatório da Coordenação da Disciplina Matemática C.E } 1^{\circ} \\
\text { Semestre; } \\
\text {-Inscrições/Documentos/Vitae; } \\
\text {-Conteúdos trabalhados nas Disciplinas de: Fundamentos; } \\
\text { Cálculo I e Cálculo II; } \\
\text {-Índices e Reprovação e Evasão; } \\
\text {-Relatório da Coordenação de Geometria Analítica e Álgebra } \\
\text { Linear; } \\
\text {-Relatórios da Coordenação da Disciplina } 20544 \text { - } \\
\text { Matemática } 2^{\circ} \text { Semestre de 1982; } \\
\text {-Arquivos Avulsos; } \\
\text {-Artigos; } \\
\text {-Curso de Estatística; } \\
\text {-Curso de Funções. }\end{array}$ \\
\hline 1983 & $\begin{array}{l}\text {-Relatórios de Disciplinas; } \\
\text {-Conteúdos trabalhados nas Disciplinas de: Geometria } \\
\text { Analítica e Álgebra Linear; Cálculo I; Cálculo II; } \\
\text {-Horário dos Professores; } \\
\text {-Manual de Elaboração de Plano de Ação Departamental; } \\
\text {-Relatório de Atividades do } 2^{\circ} \text { Semestre I; } \\
\text {-Relatório de Atividades do } 2^{\circ} \text { Semestre II; } \\
\text {-Relatório Individual de Trabalho } 1^{\circ} \text { Semestre de 1983; } \\
\text {-Relatório Individual de Trabalho } 2^{\circ} \text { Semestre de 1983; } \\
\text {-Resoluções/Documentos de } 1983 ; \\
\text {-Ementas e Programas; } \\
\text {-Relatório Final Reunião SBM. }\end{array}$ \\
\hline 1984 & $\begin{array}{l}\text {-Horário dos Professores; } \\
\text {-Livro Documentado de Resoluções Vigentes - Colegiado do } \\
\text { Curso de Matemática I; } \\
\text {-Livro Documentado de Resoluções Vigentes - Colegiado do } \\
\text { Curso de Matemática II; } \\
\text {-Ementas e Programas (Algumas); }\end{array}$ \\
\hline 1985 & $\begin{array}{l}\text {-Ementas e Programas; } \\
\text {-Relatórios Individual de Atividades Docentes; } \\
\text {-Plano Global I; } \\
\text {-Plano Global II; } \\
\text {-Mapa Resumo de Atividades de Professores; } \\
\text {-Horário dos Professores; } \\
\text {-Ementas e Programas de Disciplinas; } \\
\text {-Arquivos de DME; }\end{array}$ \\
\hline
\end{tabular}


Suélen Rita Andrade Machado; Lucieli M. Trivizoli

Uma história para o inventário arquivístico do departamento de matemática da UEM

\begin{tabular}{|c|c|}
\hline & -Editais de Curso de Especialização. \\
\hline 1986 & $\begin{array}{l}\text {-Horário de Aulas (Disciplinas) I; } \\
\text {-Horário de Aulas (Disciplinas) II; } \\
\text {-Mapa Resumo das Atividades Docentes; } \\
\text {-Relatórios Plano Global; } \\
\text {-Plano Global I; } \\
\text {-Plano Global II; } \\
\text {-Plano Global III; } \\
\text {-Plano Global IV; } \\
\text {-Plano Global V; } \\
\text {-Ofícios; } \\
\text {-Documentos; } \\
\text {-Justificativa de Ausências em Reuniões; } \\
\text {-Recortes de jornal Pós-Graduação de } 1986 \text { a } 1987 .\end{array}$ \\
\hline 1987 & $\begin{array}{l}\text {-Regulamento dos Colegiados de Curso; } \\
\text {-Proposta de Desmembramento do Departamento de } \\
\text { Matemática e Estatística; } \\
\text {-Plano Global 01/1987 I; } \\
\text {-Plano Global 01/1987 II; } \\
\text {-Plano Global 01/1987 III; } \\
\text {-Plano Global 02/1987 I; } \\
\text {-Plano Global 02/1987 II; } \\
\text {-Plano Global 02/1987 III; } \\
\text {-Ementas e Programas (Algumas). }\end{array}$ \\
\hline 1988 & $\begin{array}{l}\text {-Ementas e Programas; } \\
\text {-Mapa Resumo das Atividades Departamentais (1988 a } \\
\text { 1992); } \\
\text {-Plano Global } 1988 \mathrm{I} \text {; } \\
\text {-Plano Global } 1988 \mathrm{II} ; \\
\text {-Plano Global } 1988 \mathrm{III} ; \\
\text {-Plano Global } 1988 \mathrm{IV} ; \\
\text {-Plano Global } 1988 \mathrm{~V} ; \\
\text {-Plano Global } 1988 \mathrm{VI} ; \\
\text {-Plano Global } 1988 \text { VII; } \\
\text {-II ENEM-UEM (Arquivos); } \\
\text {-II Plano de Desenvolvimento da UEM (1988 a 1991); } \\
\text {-OBMEP 1988. }\end{array}$ \\
\hline 1989 & $\begin{array}{l}\text {-Ementas e Programas (Algumas); } \\
\text {-Mapa Resumo das Atividades Departamentais (1988 a } \\
\text { 1992); } \\
\text {-Plano Global } 1989 \text { I; } \\
\text {-Plano Global } 1989 \text { II; } \\
\text {-Plano Global } 1989 \text { III; } \\
\text {-Plano Global } 1989 \text { IV; } \\
\text {-Plano Global } 1989 \text { V; } \\
\text {-Plano Global } 1989 \text { VI; } \\
\text {-Plano Global } 1989 \text { VII; } \\
\text {-Ficha de Horário de Disciplina do } 2^{\circ} \text { Semestre de 1989; } \\
\text {-Ofício/Plano Global. }\end{array}$ \\
\hline 1990 & -Ementas e Programas (Algumas). \\
\hline 1991 & $\begin{array}{l}\text {-Regulamento do Colegiado do Curso; } \\
\text {-Projeto Pedagógico (Currículo) do Curso de Matemática, } \\
\text { Vol. 1; } \\
\text {-Projeto Pedagógico (Currículo) do Curso de Matemática, } \\
\text { Vol. 2; } \\
\text {-Criação do Bacharelado em Matemática e Reformulação da } \\
\text { Licenciatura. }\end{array}$ \\
\hline 1992 & $\begin{array}{l}\text {-Ementas e Programas (Algumas); } \\
\text {-Resoluções (Pós-Graduação). }\end{array}$ \\
\hline
\end{tabular}


Suélen Rita Andrade Machado; Lucieli M. Trivizoli

Uma história para o inventário arquivístico do departamento de matemática da UEM

\begin{tabular}{|c|l|}
\hline 1993 & $\begin{array}{l}\text {-Ementas e Programas (Algumas); } \\
\text {-Resolução. }\end{array}$ \\
\hline 1994 & $\begin{array}{l}\text {-Relatório Individual de Atividades Docente; } \\
\text {-Especialização em Matemática 1994. }\end{array}$ \\
\hline 1992 A 1996 & $\begin{array}{l}\text {-Arquivos referentes a Pós-Graduação em Matemática } \\
\text { oferecido pelo Departamento 1994 a 1996: Programas, Notas } \\
\text { de Alunos, Monografias, Relatórios de Disciplina da } \\
\text { Especialização; } \\
\text {-Documentos avulsos. }\end{array}$ \\
\hline
\end{tabular}

Fonte: Adaptado de Machado (2019)

Atualmente, o inventário arquivístico do Departamento de Matemática da Universidade Estadual de Maringá obteve autorização por meio do projeto de pesquisa institucional e foi transferido da sala de máquinas, para a sala 121 , bloco F67, $2^{\circ}$ andar. Todos os materiais foram organizados em pasta-arquivos em conformidade à data cronológica, justapostos em estantes e podem ser consultados mediante contato prévio conosco.

\section{Considerações finais}

Neste artigo, caracterizamos o processo de preservação da memória institucional do Departamento de Matemática da Universidade Estadual de Maringá, a partir da identificação e organização de um inventário arquivístico, datado entre 1971 a 1996. Conforme observamos, este foi um processo intenso e longo, que corresponde a parte da História Institucional desse Curso.

Esse processo não transcorreu instantaneamente, mas sucedeu de diligências de um grupo de pesquisadores que se comprometeu com a função de coletar e organizar estes documentos, em prol da construção de uma História para o Curso de Matemática da UEM, considerando personagens e currículos. Embora, o objetivo traçado não fosse pensado no inventário que aqui apresentamos, todo o esforço dos pesquisadores corroborou no sentido de que o recém construído inventário arquivístico do Departamento de Matemática da UEM fosse divulgado publicamente.

Este esforço e desvio de objetivo, culmina na fala de Dominique Julia, ao afirmar que o historiador constrói flechas com qualquer artefato de madeira (JULIA, 2001). Reiteramos aqui, que o termo "qualquer" não significa que os documentos sejam menosprezáveis, pelo contrário, eles possibilitam a preservação da história brasileira e da História da Matemática no Brasil. 
Suélen Rita Andrade Machado; Lucieli M. Trivizoli

Uma história para o inventário arquivístico do departamento de matemática da UEM

Assim, entendemos que a divulgação deste inventário pode fortalecer o cenário investigativo na construção de conhecimentos históricos pluridisciplinares pelos vieses historiográficos de abrangência diversas, em nosso caso específico, pela História da Matemática e História da Educação Matemática do Paraná para o Brasil.

\section{Referências}

ARAUJO NETO, Antonio Peixoto de. Um estudo histórico do curso de matemática da Universidade Estadual de Maringá: a criação e os primeiros anos. Dissertação (Mestrado em Educação em Ciência e Matemática), Universidade Estadual de Maringá, Centro de Ciências Exatas, Programa de Pós-Graduação em Educação para a Ciência e a Matemática, Maringá, PR, 2016.

ARAUJO NETO, Antonio Peixoto de; GOMES, Leticia Dayane; TRIVIZOLI, Lucieli Maria. Um estudo histórico do Curso de Matemática da Universidade Estadual de Maringá: primeiras observações. In: X SEMINÁRIO NACIONAL DE HISTÓRIA DA MATEMÁTICA, 2013. Campinas-SP. Anais... do X Seminário Nacional de História da Matemática. Campinas-SP, 2013. Disponível em: < https://www.cle.unicamp.br/eprints/index.php/anais-snhm/article/view/40 >. Acesso em: 30 jul. 2019.

\section{ARQUIVO NACIONAL (BRASIL). Dicionário Brasileiro de Terminologia} Arquivística. Rio de Janeiro: Arquivo Nacional, 2005.

BACELLAR, Carlos. Fontes Documentais: Uso e mau uso dos arquivos. In: PINSKY, Carla Bassanezi (Org.). Fontes históricas. São Paulo: Contexto, 2008.

BOGDAN, Robert; BIKLEN, Sari. Investigação qualitativa em educação: fundamentos, métodos e técnicas. Portugal: Porto Editora, 1994.

FLAVIO, Deivid Maicon; TRIVIZOLI, Lucieli Maria. Identificação de documentos do Departamento de Matemática da UEM. In: XXIV EAIC - ENCONTRO ANUAL DE INICIAÇÃO CIENTÍFICA, 24., 2015. Maringá. Anais... Maringá: EAIC, 2015. Disponível em: < http://www.eaic.uem.br/eaic2015/anais/artigos/235.pdf >. Acesso em: 30 jul. 2019.

FLICK, Uwe. Uma introdução à pesquisa qualitativa. Trad. Sandra Netz. 2. ed. Porto Alegre, RS: Bookman, 2004.

GARNICA, Antonio Vicente Marafioti; SOUZA, Luzia Aparecida de. Elementos de história da educação matemática. São Paulo: Cultura Acadêmica, 2012.

GOMES, Letícia Dayane; TRIVIZOLI, Lucieli Maria. Histórico das disciplinas do curso de matemática da UEM. In: XXIV EAIC - ENCONTRO ANUAL DE INICIAÇÃO CIENTÍFICA, 24., 2015. Maringá. Anais... Maringá: EAIC, 2015. Disponível em: < http://www.eaic.uem.br/eaic2015/anais/artigos/299.pdf>. Acesso em: 19 ago. 2019. 
INDOLFO, Ana Celeste. Gestão de documentos: uma renovação epistemológica no universo da Arquivologia. Arquivística.net, v. 3, n. 2, p. 28-60, 2007. Disponível em: <www.arquivistica.net>. Acesso em: 30 jul. 2019.

JULIA, Dominique. A cultura escolar como objeto histórico. Revista Brasileira de História da Educação, v. 1, p. 9-44, 2001.

MACHADO, Suélen Rita Andrade. As modificações curriculares do Curso de Matemática da Universidade Estadual de Maringá: mudanças no saber profissional do professor de matemática, 1971-1996. 155f. Dissertação (Mestrado em Educação para a Ciência e a Matemática) - Universidade Estadual de Maringá, Maringá-PR, 2019.

MACHADO, Suélen Rita Andrade; TRIVIZOLI, Lucieli Maria. Um estudo sobre as modificações curriculares do curso de matemática da UEM: primeiras impressões de pesquisa. In: II ÁGORA, 2., 2018. Campo Mourão. Anais... Campo Mourão: AGORA, 2018a. Disponível em: < http://www.fecilcam.br/eventos/index.php/agoramatematica/iiagora/paper/view/6165 >. Acesso em: 30 jul. 2019.

MACHADO, Suélen Rita Andrade; TRIVIZOLI, Lucieli M. I Encontro do ensino da matemática na UEM (Maringá, 1981): componente histórica da Educação Matemática no Brasil. Revista Paranaense de Educação Matemática, v. 7, n. 14, 2018 b.

MARCONI, Marina de Andrade; LAKATOS, Eva Maria. Fundamentos de metodologia científica. 5. ed. São Paulo: Atlas, 2003. 